Review

\title{
A Global Survey of Current Zoo Housing and Husbandry Practices for Fossa: A Preliminary Review
}

\author{
Jessica J. Harley ${ }^{1,2, *(D)}$, Lisa $O^{\prime}$ Hara $^{1}$ and Paul E. Rose ${ }^{3,4}(\mathbb{D}$ \\ 1 Department of Conservation, Education \& Research, Tayto Park, A84 EA02 Meath, Ireland; \\ education@taytopark.ie \\ 2 Animal Behaviour \& Welfare Research Group, Department of Biological Sciences, University of Chester, \\ Chester CH1 4BJ, UK \\ 3 Centre for Research in Animal Behaviour, Psychology, Washington Singer, University of Exeter, Perry Road, \\ Exeter EX4 4QG, UK; p.rose@exeter.ac.uk \\ 4 Wildfowl \& Wetlands Trust, Slimbridge Wetland Centre, Slimbridge, Gloucestershire GL2 7BT, UK \\ * Correspondence: 1914124@chester.ac.uk
}

check for

updates

Citation: Harley, J.J.; O'Hara, L.; Rose, P.E. A Global Survey of Current Zoo Housing and Husbandry Practices for Fossa: A Preliminary Review. J. Zool. Bot. Gard. 2021, 2, 388-405. https://doi.org/ $10.3390 /$ jzbg2030028

Received: 1 June 2021

Accepted: 16 July 2021

Published: 20 July 2021

Publisher's Note: MDPI stays neutral with regard to jurisdictional claims in published maps and institutional affiliations.

Copyright: (c) 2021 by the authors. Licensee MDPI, Basel, Switzerland. This article is an open access article distributed under the terms and conditions of the Creative Commons Attribution (CC BY) license (https:/ / creativecommons.org/licenses/by/ $4.0 /$ )

\begin{abstract}
The fossa is a specialized Malagasy carnivore housed in ex situ facilities since the late 19th century. Moderate breeding success has occurred since the 1970s, and welfare issues (notably stereotypic pacing behaviour) are commonly documented. To understand challenges relating to fossa housing and husbandry $(\mathrm{H} \& \mathrm{H})$ across global facilities and to identify areas of good practice that dovetail with available husbandry standards, a survey was distributed to ZIMS-registered zoos in 2017. Results showed that outdoor housing area and volume varied greatly across facilities, the majority of fossa expressed unnatural behaviours, with pacing behaviour the most frequently observed. All fossa received enrichment, and most had public access restricted to one or two sides of the enclosure. The majority of fossa were locked in/out as part of their daily management and forty-one percent of the fossa surveyed as breeding individuals bred at the zoo. Dense cover within an enclosure, restricted public viewing areas, a variable feeding schedule and limited view of another species from the fossa exhibit appear to reduce the risk of unnatural behavior being performed. The achievement of best practice fossa husbandry may be a challenge due to its specialized ecology, the limited wild information guiding captive care, and the range of housing dimensions and exhibit features provided by zoos that makes identification of standardized practices difficult. We recommended that holders evaluate how and when enrichment is provided and assess what they are providing for environmental complexity as well as consider how the public views their fossa.
\end{abstract}

Keywords: evidence-based practice; zoo husbandry; small carnivores

\section{Introduction}

Despite the numerous advances in the housing and husbandry $(\mathrm{H} \& \mathrm{H})$ and welfare of animals in managed care [1-3], there are still gaps in our knowledge for many zoo species. Further development in evidence-based H\&H, incorporating natural history and behavioural ecology, that promotes evidence-based best practice, is required [1,4]. The importance of wild ecology in zoo animal management has been highlighted in recent studies using comparative methods to identify species-level risk factors for stereotypical behaviour in carnivores [5-7]. Clubb and Mason [5] concluded that long daily traveling distances and wide-ranging large-bodied species were associated with an increased risk of expressing stereotypical behaviour in managed care. Kroshko [7] replicated these findings, adding that range size-effect was independent of body size and established that long chase distances were also a predictor for stereotypic pacing. These studies elucidate the need for an animal's behavioural ecology and natural history to be central in the development and review of H\&H best-practice for zoo animals. Furthermore, conditions of captivity $(\mathrm{H} \& \mathrm{H})$ may result in physiological stress, in which the stress response triggers hormonal, 
physiological and behavioural responses to help an animal survive potentially aversive stimuli [8]. While these responses are adaptive, chronic stress may cause increased secretion of glucocorticoids, reduced fecundity, inactivity or stereotypic behaviours, thus impacting the welfare of the animal [8-10].

Where gaps in current knowledge of species management exist, global H\&H surveys can succinctly characterize critical aspects of good practice [11,12] and provide a foundation for developing best-practice $\mathrm{H} \& \mathrm{H}$ guidelines. For those species with $\mathrm{H} \& \mathrm{H}$ guidelines, a global survey can identify areas where facilities are not meeting or may have deviated from prescribed H\&H recommendations [12,13]. Nevertheless, such publications are rare with only a handful of species represented in the literature, e.g., Malayan tapir (Tapirus indicus) [11], primates (Loris sp. \& Nycticebus sp) [13], banteng (Bos javanicus) [12], Burmese brow antlered deer (Rucerous eldii thamin) [14], hippopotamus (Hippopotamus amphibius) [15], and lechwe (Kobus sp.) [16] and is indicative that more work in this area is required.

The fossa (Cryptoprocta ferox) is categorized as Vulnerable by the IUCN [17] and is the largest of eight extant endemic Malagasy carnivores in the monophyletic family Eupleridae. Eupleridae is among the most threatened of carnivore families but one of the least studied [18]. Fossa are cathemeral [19], hunt their prey both terrestrially and arboreally, and are the only non-primate mammal to consume a high proportion of primates in their diet [20]. Fossa are mainly solitary [21] but have been reported to socially hunt in pairs [22]. Fossa have large home ranges, traveling up to 5-7 km per day [23-25]; males occupy larger territories $\left(>20 \mathrm{~km}^{2}\right)$, which overlap with other males, and females inhabit exclusive ranges of 7-13 $\mathrm{km}^{2}$ [26]. Despite their wide distribution in Madagascar's western and eastern forests, population densities are lower than predicted by body size [26]. Fossa utilize a unique mating system where females will monopolize a site (e.g., high up in a tree) and maximize the available number of mates [26,27]. Transient masculinization, defined as the temporary enlargement of the spinescent clitoris supported by an os clitoridis (baubellum) of young females 1-2 years of age has been described by Hawkins [28]. The male traits become prominent around dispersal, and it has been postulated that this may be a mechanism to reduce male sexual harassment of young females or enable female fossa to evade aggression from territorial females [28].

Fossa have been housed ex situ since as early as the 19th century [29]. Captive breeding of fossa in Europe began in 1974 at Montpellier Zoo, France [30] and in the United States in 1989 at San Diego Zoo [31]. As of 17 October 2018, Species360 Zoological Information Systems (ZIMS) revealed that 47 zoological institutions in Asia, Europe, and North America house 65 males, 50 females, and two of undetermined sex, giving a total population of 117 individuals [32]. Fossa are challenging to breed, and since the establishment of the breeding programs, the population has slowly increased [33]. However, 2017 was a particularly notable year for the European breeding program, with fourteen total births, of which eight were at Duisburg Zoo, Germany [34]. Nevertheless, both the American Zoological Association (AZA) Breeding and Transfer Plan and the European Endangered Species Programme (EEP) have not yet met their target population for their respective programs $[34,35]$. During the last two decades, the fossa population has decreased by more than $30 \%$, with recent estimates ranging between 2635 and 8626 fossa in the wild $[17,19]$. The continued fragmentation of forest habitat, hunting for food, and persecution resulting from human/animal conflict suggests a further drop in the population will occur over the next three generations $[17,36]$. This rapid decline in the wild population of fossa coupled with continuing fragmentation of forest habitat indicates that the captive population and managed breeding programs will become increasingly important to ensure this species ${ }^{\prime}$ persistence.

This review of the ecology of the fossa is important for our understanding of its management and welfare experience in captivity. The style of reproductive interactions for fossa, is not predicted by mating system theory and is unique for a solitary carnivore [27]. The large home ranges, daily travel distances and the fossa's hunting style which includes both arboreal and terrestrial pursuit of prey, are key behavioural and ecological adaptations; 
knowledge of which is beneficial to the evaluation of managed care practices. Such information should be considered when assessing the suitability of captive care as conservation of evolutionary adaptations in ex situ housed individuals are important for the future viability of populations and strengthen the potential of such individuals to be included in conservation planning in the future. Consideration of the behavioural biology of ex situ individuals and the influences of this on conservation planning is now more important in light of the IUCN's One Plan Approach to conservation that calls for credible conservation relevance of individuals under human care [37,38].

Although there is a lack of empirical study, husbandry guidelines are available for this species offering a broad review of the current knowledge of fossa care and husbandry [39,40]. With the relatively low output of research on captive and wild fossa, a study of current H\&H practices will facilitate increased understanding of this species, which may inform future best practice. The study aimed to investigate: (1) the demographic and population characteristics of fossa housed in zoological collections (2) $\mathrm{H} \& \mathrm{H}$ practices and whether they are consistent with current AZA and EAZA guidelines (3) the prevalence of unnatural behaviours and identify any trends in $\mathrm{H} \& \mathrm{H}$ and occurrence of these behaviours in fossa. Lastly, the authors wish to highlight areas for further empirical studies that will close gaps in our knowledge of this species' care needs.

\section{Materials and Methods}

\subsection{Survey Participants and Selection}

The contact details of zoological institutions holding fossa were sourced for Species 360 registered zoos, and a questionnaire was sent to the 47 facilities, of which 26 responded ( $55 \%$ of holders), providing a sample size of 46 individual fossa that represented $39.32 \%$ of the total (ZIMS) captive population (Table 1), as of March 2017. Facilities responding to the survey were located in Asia, Europe and the United States.

\subsection{Survey Questionnaire}

Data were collected via the distribution of an online questionnaire using SurveyMonkey Inc. (San Mateo, CA, USA). Each holder was asked to complete a survey for all fossa housed in their collection (Supplementary Materials; Survey S1). The questionnaire was divided into four sections with the following variables used in the study: (1) Subject background/general husbandry, including age, sex, origin, rearing, reproductive status, breeding success, and information regarding $\mathrm{H} \& \mathrm{H}$ practices, (2)-Indoor and outdoor enclosure sizes, and features including substrates, level of cover, trees/climbing apparatus, public viewing areas, (3) Training and enrichment including the type of enrichment provision and frequency utilized, and (4) Expression of pacing, anticipatory behaviour, head rolling, and self-directed behaviours (hereinafter referred to as unnatural behaviour) (Table 2). If the fossa expressed a behaviour that was not defined the respondent could choose 'other' and provide an open-ended response in the comment box. If the fossa expressed more than one behaviour they could choose other/combined and provide explanation of the behaviour.

Enclosure dimensions were provided by the individual at the zoo who responded to the survey. The respondent was prompted to provide a measurement or best estimated measurement of the enclosure's width, length and height. Respondents were provided with the author's contact information if they were unsure about these dimensions. Not all respondents provided enclosure dimensions (height was the most commonly missed measurement provided) and therefore it was assumed that those that did record height, width and length on the survey were providing accurate information to obtain the area and volume of the enclosure. All multiple-choice questions in the survey included 'other,' and open-ended responses were specified in the comments section. 
Table 1. Study population of fossa at each zoological collection included in the survey with information relating to the total population, the sex ratio reported as male.female, the age range of animals, and how they are housed (singly, single sex-related, breeding pair, parent w/offspring).

\begin{tabular}{|c|c|c|c|}
\hline Zoo & $\begin{array}{l}\text { Number \& Sex Ratio } \\
\text { Male.Female }\end{array}$ & Age Range & Housing \\
\hline 1 & 0.2 & $1-2$ yrs & Single sex related pair \\
\hline 2 & 1.1 & $4-10$ yrs & Singly \\
\hline 3 & 1.1 & $2-7$ yrs & Singly \\
\hline 4 & 1.1 & $10+\mathrm{yrs}$ & Singly \\
\hline 5 & 0.1 & $10+$ yrs & Singly \\
\hline 6 & 0.1 & $10+$ yrs & Singly \\
\hline 7 & 1.1 & $10+$ yrs & Singly \\
\hline 8 & 2.1 & $6-7$ yrs & Single sex related pair $(\mathrm{m})$, singly (f) \\
\hline 9 & 1.0 & $10+\mathrm{yrs}$ & Singly \\
\hline 10 & 1.1 & $10+$ yrs & Singly \\
\hline 11 & 3.1 & $1-10+$ yrs & Singly $(\mathrm{m}, \mathrm{f})$, single sex related pair $(\mathrm{m})$ \\
\hline 12 & 1.0 & $7-8$ yrs & Singly \\
\hline 13 & 2.0 & $4-5$ yrs & Singly \\
\hline 14 & 0.1 & $3-4$ yrs & Singly \\
\hline 15 & 1.0 & $4-5$ yrs & Singly \\
\hline 16 & 1.1 & $10+y r s$ & Singly \\
\hline 17 & 1.0 & $10+y r s$ & Singly \\
\hline 18 & 1.0 & $10+$ yrs & Singly \\
\hline 19 & 1.1 & $9-10+$ yrs & Singly \\
\hline 20 & 1.0 & $3-4$ yrs & Singly \\
\hline 21 & 1.1 & $8-10+y r s$ & Singly \\
\hline 22 & 1.0 & $4-5$ yrs & Singly \\
\hline 23 & 1.0 & $10+y r s$ & Singly \\
\hline 24 & 1.1 & $6-7$ yrs & Singly \\
\hline 25 & 0.1 & $10+y r s$ & Singly \\
\hline 26 & 2.3 & $1-10+$ yrs & $\begin{array}{l}\text { Singly (f), breeding pair (when female without offspring } \\
\text { (m.f)), parent (f) w/offspring (m,f) }\end{array}$ \\
\hline
\end{tabular}

$10+$ refers to a fossa that is older than 10 years of age.

Table 2. Unnatural behaviour categories and definitions from the global housing and husbandry survey (2017).

\begin{tabular}{ll}
\hline Pacing & $\begin{array}{l}\text { Any repetitive locomotion in a fixed pattern, such as back and forth along the same route or pattern } \\
\text { e.g., figure of eight. Behaviour appears to have no goal or function. }\end{array}$ \\
\hline Self-directed & $\begin{array}{l}\text { Any self-injurious behaviours, such as biting/chewing/sucking/licking, causing wounds, missing } \\
\text { fur or irritations. e.g., excessive grooming, tail/paw biting/sucking. }\end{array}$ \\
\hline Head rolling & Tossing head in circular motion \\
\hline Anticipatory & $\begin{array}{l}\text { Behaviours relating to daily cleaning/feeding routines, e.g., locomotion, vocalisations, waiting at } \\
\text { hatch, keeper-directed behaviours }\end{array}$ \\
\hline Other or Combination & Please outline in as much detail as possible the fossa's behaviour in the comment box \\
\hline
\end{tabular}




\subsection{Data Analysis}

The key aim of this investigation was to summarise the useful information, applicable to future standardisation of husbandry practices for fossa globally, from this set of survey results. We descriptively illustrate areas of common ground as well as the characteristics of the fossa population under test. We also tested any differences in reports of unnatural behaviours (as categorised and reported independently by keepers and caregivers in the survey) and breeding activity, including the presence of nest boxes.

The key null hypotheses of this study were: (1) Individual zoo husbandry and enclosure characteristics or fossa population characteristics would not influence indoor and outdoor enclosure area and volume.; (2) Reports of unnatural behaviour would not differ between facilities; (3) There would be no difference in the space provided to or number of nest boxes provided for breeding and non-breeding age fossa between facilities.

All data were analysed in Minitab v.19.2020.1, (Minitab LLC, State College, PA, USA). Data for each factor were run through an Anderson-Darling test to assess for normality.

\subsubsection{Demographic and Population Characteristics}

Descriptive analysis was produced to identify the number of individuals that information was provided on within each age category, of each sex, of what origin (wild or captive born), how they were housed and if they were or are currently breeding. Dimensions including area (length $\times$ width) and volume (length $\times$ width $\times$ height) of enclosures were illustrated using box and whisker plots to identify median dimensions plus interquartile ranges and outliers. These boxplots were drawn in Minitab and MedCalc (MedCalc Software, Ostend, Belgium) for a subsample of fossa where zoos had provided all required housing measures $(\mathrm{N}=36)$.

To identify any significant differences reported in the indoor area, outdoor area and outdoor height of the enclosures provided at each zoo according to the sex, age, number per enclosure, access on or off show (yes/no), ability to hide from visitors (yes/no) and continent where the zoo was located (Europe/America, $\mathrm{N}=35$ ) a Kruskal-Wallis test was run for each factor and each outcome variable.

To test whether there was a significant association between the sex of the fossa and being shut in or outside, and whether there was any association between the sex of the fossa and being housed in an enclosure that did or did not enable escape from public viewing, one-way Chi-squared tests were run.

\subsubsection{Reports of Unnatural Behaviour from the Survey Responses}

To analyse any association between the sex of the fossa and reported performance of unnatural behaviour, a cross tabulation and Likelihood-ratio Chi-squared test (chosen as most suitable for small sample sizes) was run using a two-way table of sex against yes/no reports of unnatural behaviour. The same testing was run to test for any association between: Public viewing (no viewing, one viewing area and more than two viewing areas) and unnatural behaviour, and between the animal that a fossa could see from its enclosure (no animal, another fossa, a prey species, a mixture of species) and reported unnatural behaviour. Enrichment, density of cover within an enclosure and feeding schedule, as well as outdoor enclosure area and outdoor enclosure height, and finally the origin (wild or captive) and age (adult, old adult and juvenile) for reports of unnatural behaviour or not were also examined descriptively.

\subsubsection{Reports of Reproductive Success from the Survey Responses}

Descriptive analysis were run on enclosure dimensions and on the number of nest boxes provided to breeding and non-breeding fossa to illustrate any differences in space provided to fossa that had breeding individuals compared to those non-breeding animals. 


\section{Results}

This survey provides information on a sample size of 46 individual fossa housed across 26 institutions around the world (Asia $=1$; Europe $=14$; USA $=11$ ). The biggest single population at a subject facility was five animals. A majority of surveys were filled in by keepers/senior keepers $(N=17)$ with section heads $(N=15)$ and curators $(N=8)$ also being highly represented. Two surveys were completed by registrars, two by zoo scientists and two by the zoo's director.

\subsection{Demographic and Population Information}

There were 20 female fossa included in the same population and 26 males (Figure 1). Most animals were in the older (post-10 years old) age group. Only three animals were wild caught with 42 individuals being bred in captivity and there was one animal of unknown origin. Of these wild caught animals, two were female and one was male. Perhaps not surprisingly, these animals are all found in the oldest age bracket of the sample population.

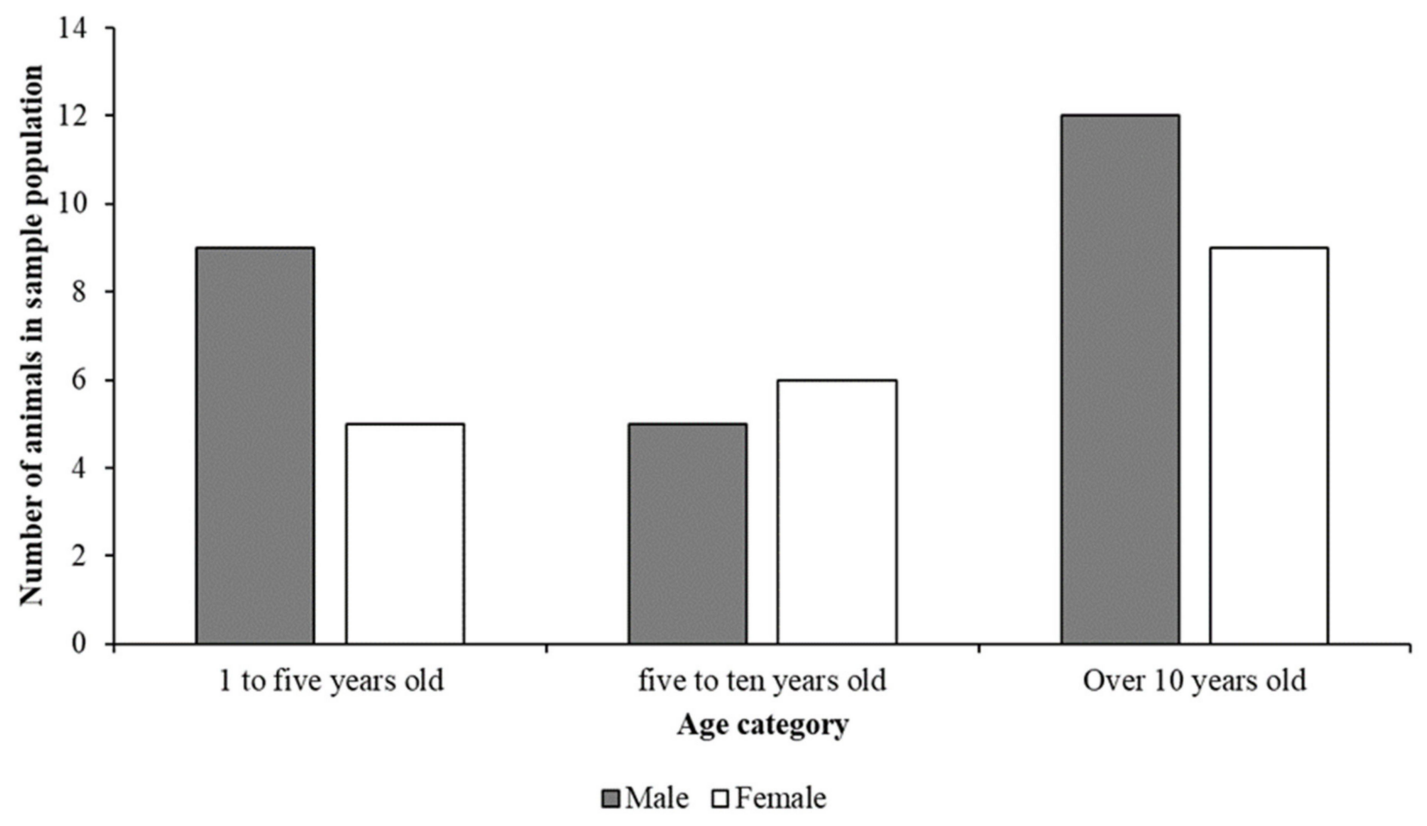

Figure 1. Age categories of each fossa included in the survey.

The majority of fossa were housed singly $(\mathrm{N}=36)$. Six individuals were housed as single-sex related pairs, two were youngsters housed with their parent, and one was housed as part of this breeding pair. Most zoos reported non-breeding, with 31 animals not reproducing and 13 having bred. Two responses were not applicable. However, 22 of the animals were of breeding age/condition and 24 were not. Most animals were parent reared $(\mathrm{N}=41)$ with four being hand-reared and one unknown rearing method.

\section{Fossa Housing and Husbandry}

For zoos that provided complete details on enclosure height, width and length of both indoor and outdoor exhibits (the subset of 36 individual fossa) there was a wide range noted in the amount of three-dimensional space provided. The median (IQR) outdoor area was 60 (34.5 to 100) $\mathrm{m}^{2}$, the outdoor volume was $307.5(126-600) \mathrm{m}^{3}$. The median (IQR) indoor area was $9.5(5.54-12.50) \mathrm{m}^{2}$ and indoor volume was $25(12.81-43.83) \mathrm{m}^{3}$. There was greater variation in outdoor area and volume compared to other measures (Figure 2). The largest outdoor enclosure provided an area of $252 \mathrm{~m}^{2}$, the smallest outdoor area was $6.25 \mathrm{~m}^{2}$., when adding height to evaluate the overall space provided the enclosure with the largest outdoor volume was $2400 \mathrm{~m}^{3}$ and the smallest was $12.5 \mathrm{~m}^{3}$ (Figure 2). This is likely reflective of a lack of standardised size and shape for fossa housing across zoos. 
A.

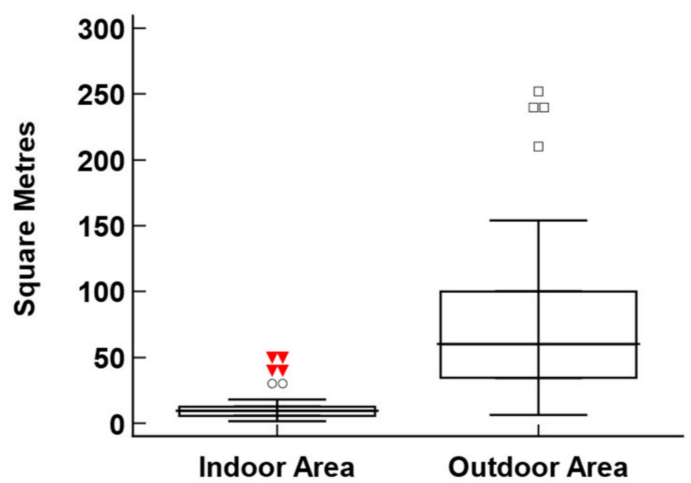

B.

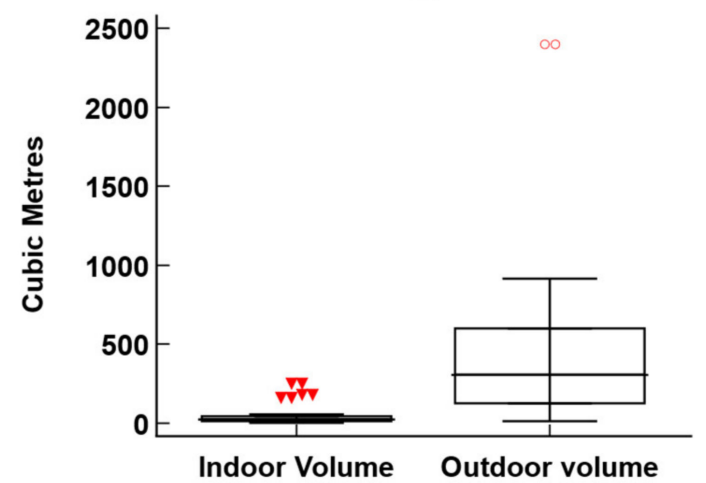

Figure 2. Variation in space provided to individual fossa across sample zoos that provided data on indoor and outdoor (A) area in square metres (length $\times$ width) and $(\mathbf{B})$ volume in cubic metres (length $\times$ width $\times$ height).

Table 3 illustrates the results of Kruskal-Wallis testing for different factors of the population surveyed compared to areas of indoor and outdoor enclosures, and outdoor height. Indoor areas were larger in enclosures for animals in European zoos compared to those in the USA and that age of the animal may influence the amount of indoor space provided, with younger animals given more area than adults (this result only approached significance). There is no difference between the sexes of fossa (male and female) and whether they were likely to be locked in or out. Thirteen female animals were likely to locked in/out and 17 male animals. Male fossa were more likely to be housed in an enclosure that provided no escape from public viewing compared to female fossa, but this relationship was not significant $(\chi 2=2.25, \mathrm{df}=1 ; \mathrm{P}=0.134)$.

Table 3. Differences in housing of animals in this survey using 36 responses that provided all enclosure measurements and 35 responses for continent (excluding the one response).

\begin{tabular}{|c|c|c|c|}
\hline Factor & Indoor Area & Outdoor Area & Outdoor Height \\
\hline Sex & $\begin{array}{c}\text { No significant difference } \\
\mathrm{H}=0.64 ; \mathrm{df}=1 ; \mathrm{P}=0.425 \\
\text { Female: } 11.25 \mathrm{~m}^{2} \\
\text { Male: } 10 \mathrm{~m}^{2}\end{array}$ & $\begin{array}{l}\text { No significant difference } \\
\mathrm{H}=2.14 ; \mathrm{df}=1 ; \mathrm{P}=0.144 \\
\text { Female: } 94.8 \mathrm{~m}^{2} \\
\text { Male: } 50 \mathrm{~m}^{2}\end{array}$ & $\begin{array}{c}\text { No significant difference } \\
\mathrm{H}=1.62 ; \mathrm{df}=1 ; \mathrm{P}=0.203 \\
\text { Female: } 6 \mathrm{~m} \\
\text { Male: } 4.5 \mathrm{~m}\end{array}$ \\
\hline Age & $\begin{array}{c}\text { Approaches significance } \\
\mathrm{H}=5.15 ; \mathrm{df}=2 ; \mathrm{P}=0.076 \\
\text { Young: } 14.61 \mathrm{~m}^{2} \\
\text { Adult: } 9 \mathrm{~m}^{2} \\
\text { Old adult: } 10 \mathrm{~m}^{2}\end{array}$ & $\begin{array}{c}\text { No significant difference } \\
\mathrm{H}=0.77 ; \mathrm{df}=2 ; \mathrm{P}=0.680 \\
\text { Young: } 94.8 \mathrm{~m}^{2} \\
\text { Adult: } 49.5 \mathrm{~m}^{2} \\
\text { Old adult: } 73.3 \mathrm{~m}^{2}\end{array}$ & $\begin{array}{c}\text { No significant difference } \\
\mathrm{H}=0.92 ; \mathrm{df}=2 ; \mathrm{P}=0.631 \\
\text { Young: } 4.5 \mathrm{~m} \\
\text { Adult: } 6 \mathrm{~m} \\
\text { Old adult: } 4.75 \mathrm{~m}\end{array}$ \\
\hline Number in enclosure & $\begin{array}{c}\text { No significant difference } \\
\mathrm{H}=2.95 ; \mathrm{df}=1 ; \mathrm{P}=0.09 \\
\text { Single: } 9.5 \mathrm{~m}^{2} \\
\text { Multiple: } 14.61 \mathrm{~m}^{2}\end{array}$ & $\begin{array}{c}\text { No significant difference } \\
\mathrm{H}=0.84 ; \mathrm{df}=1 ; \mathrm{P}=0.361 \\
\text { Single: } 50 \mathrm{~m}^{2} \\
\text { Multiple: } 94.8 \mathrm{~m}^{2}\end{array}$ & $\begin{array}{c}\text { No significant difference } \\
\mathrm{H}=0.22 ; \mathrm{df}=1 ; \mathrm{P}=0.641 \\
\text { Single: } 5.5 \mathrm{~m} \\
\text { Multiple: } 4.5 \mathrm{~m}\end{array}$ \\
\hline Shut on/off show? & $\begin{array}{c}\text { No significant difference } \\
\mathrm{H}=0.17 ; \mathrm{df}=1 ; \mathrm{P}=0.680 \\
\text { Yes: } 10 \mathrm{~m}^{2} \\
\text { No: } 10.5 \mathrm{~m}^{2}\end{array}$ & $\begin{array}{c}\text { No significant difference } \\
\mathrm{H}=0.14 ; \mathrm{df}=1 ; \mathrm{P}=0.705 \\
\text { Yes: } 76.5 \mathrm{~m}^{2} \\
\text { No: } 45.5 \mathrm{~m}^{2}\end{array}$ & $\begin{array}{c}\text { No significant difference } \\
\mathrm{H}=0.57 ; \mathrm{df}=1 ; \mathrm{P}=0.450 \\
\text { Yes: } 6 \mathrm{~m} \\
\text { No: } 4 \mathrm{~m}\end{array}$ \\
\hline Escape from public viewing? & $\begin{array}{c}\text { No significant difference } \\
\mathrm{H}=1.34 ; \mathrm{df}=1 ; \mathrm{P}=0.248 \\
\text { Yes: } 10 \mathrm{~m}^{2} \\
\text { No: } 14.61 \mathrm{~m}^{2}\end{array}$ & $\begin{array}{c}\text { No significant difference } \\
\mathrm{H}=1.78 ; \mathrm{df}=1 ; \mathrm{P}=0.182 \\
\text { Yes: } 48 \mathrm{~m}^{2} \\
\mathrm{No}=94.8 \mathrm{~m}^{2}\end{array}$ & $\begin{array}{c}\text { No significant difference } \\
\mathrm{H}=0.01 ; \mathrm{df}=1 ; \mathrm{P}=0.933 \\
\text { Yes: } 5 \mathrm{~m} \\
\text { No: } 4.5 \mathrm{~m}\end{array}$ \\
\hline Continent & $\begin{array}{c}\text { Significant difference } \\
\mathrm{H}=5.50 ; \mathrm{df}=1 ; \mathrm{P}=0.02 \\
\text { Europe: } 10.3 \mathrm{~m}^{2} \\
\text { USA: } 6.25 \mathrm{~m}^{2}\end{array}$ & $\begin{array}{l}\text { No significant difference } \\
\mathrm{H}=1.64 ; \mathrm{df}=1 ; \mathrm{P}=0.20 \\
\text { Europe: } 60 \mathrm{~m}^{2} \\
\text { USA: } 70 \mathrm{~m}^{2}\end{array}$ & $\begin{array}{l}\text { No significant difference } \\
\mathrm{H}=1.9 ; \mathrm{df}=1 ; \mathrm{P}=0.168 \\
\text { Europe: } 6 \mathrm{~m} \\
\text { USA: } 4.5 \mathrm{~m}\end{array}$ \\
\hline
\end{tabular}




\subsection{Reports of Unnatural Behaviour}

Across all survey responses, 32 fossa were documented as performing unnatural behaviour (70\%). For these animals $56 \%$ were reported as pacing, $13 \%$ performed both pacing and anticipatory behaviour and $28 \%$ performed anticipatory behaviours. One fossa was documented as performing self-directed behaviour. The most common unnatural behaviour reported in both male (46\%) and female fossa (30\%) was pacing, and more male fossa were reported to perform anticipatory behaviour compared to females ( $23 \%$ compared to $15 \%$ ).

Equal numbers of female fossa were reported as performing unnatural behaviour (10 yes and 10 no), but more male fossa presented with unnatural behaviour $(\mathrm{N}=22)$ compared to $\operatorname{not}(\mathrm{N}=4)$. A cross tabulation and Chi-squared analysis showed there to be a significant association between sex of the animal and performance of unnatural behaviour (likelihood ratio $\chi 2=6.09 ; \mathrm{df}=1 ; \mathrm{P}=0.014)$. Figure 3 shows that, whilst differences are not significant (Table 1), female fossa represented in this survey were provided with more space than male fossa and this may explain the significant difference in higher performance of unnatural behaviour for male animals.
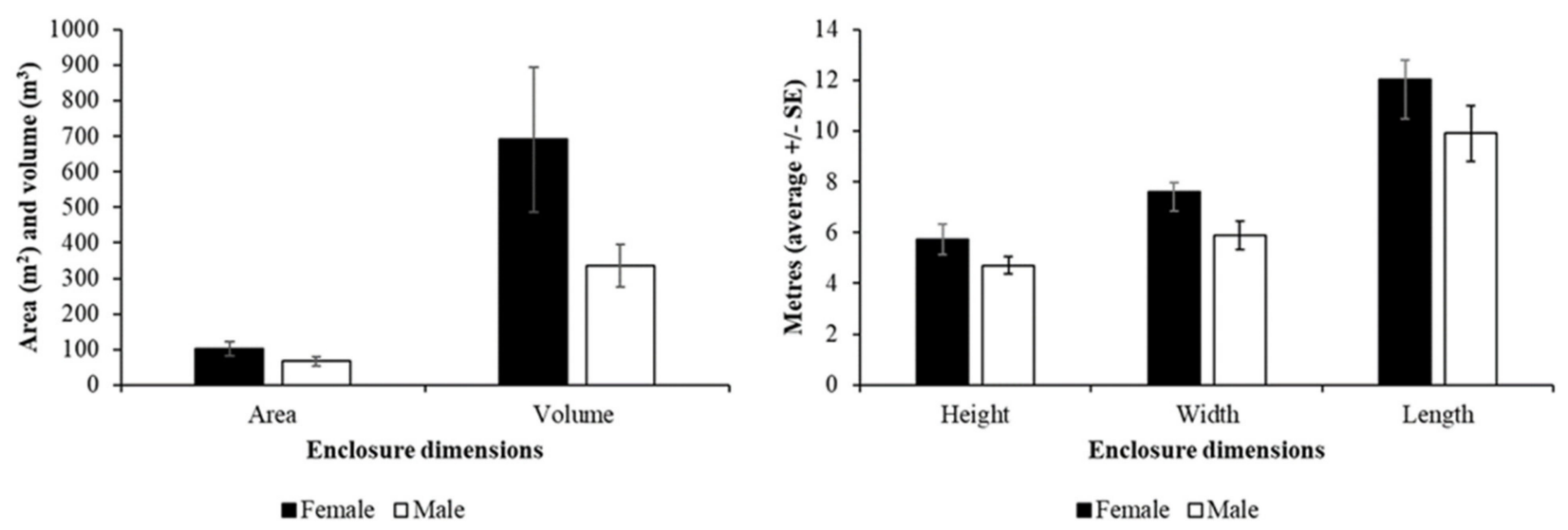

Figure 3. Mean $( \pm \mathrm{SE})$ of outdoor enclosure area, volume and dimensions for male and female fossa $(\mathrm{N}=36)$ were all enclosure measurements were provided.

The mean outdoor area provided to fossa that did not perform unnatural behaviour was $96.4( \pm 23.5) \mathrm{m}^{2}$ compared to $73.6( \pm 12.5) \mathrm{m}^{2}$ for animals that were reported as performing unnatural behaviour. Height differences vary only slightly for animals that reported as not performing unnatural behaviour $(5.2 \pm 0.8 \mathrm{~m})$ and performing unnatural behaviour $(5.1 \pm 0.33 \mathrm{~m})$.

Reports of unnatural behaviour increase when fossa experience more public viewing (Figure 4). A cross tabulation and Chi-squared using the likelihood-ratio showed a significant association between the number of viewing points and reports of unnatural behaviour (Likelihood ratio $\chi 2=10.68 ; \mathrm{df}=1 ; \mathrm{P}=0.03$ ), suggesting that more viewing points equates to increased performance of unnatural behaviour.

More fossa were reported to display unnatural behaviour when in proximity (in view) to a conspecific or other animal from their enclosure (Figure 5). This association between the type of view and reports of unnatural behaviour was significant (likelihood ratio $\times 2=$ $15.58 ; \mathrm{df}=6 ; \mathrm{P}=0.016$ ). When fossa were reported as performing unnatural behaviour, this was higher for animals that were not provided with a choice to be on or off show (66\%). 


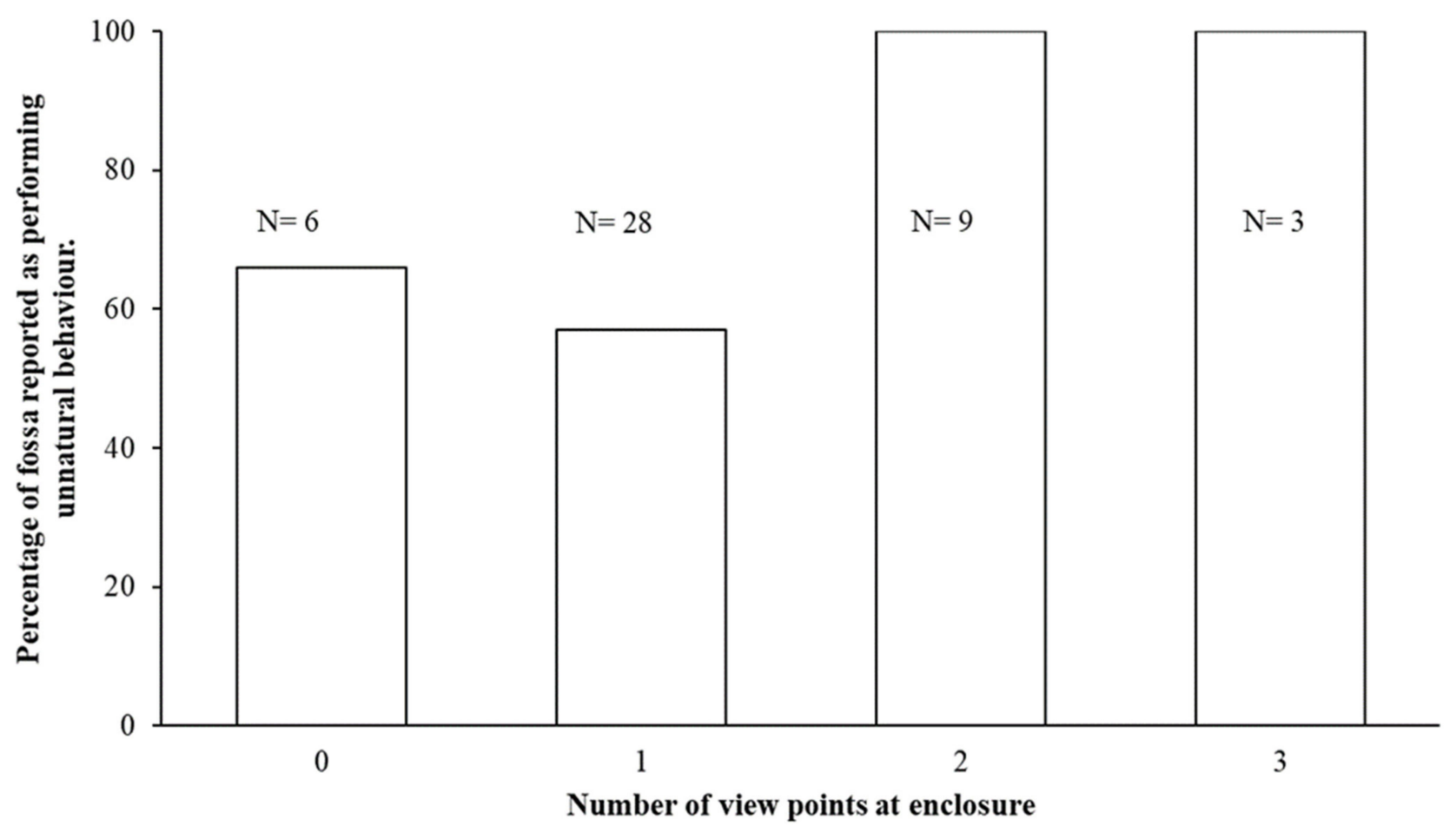

Figure 4. Percentage of observations of unnatural behaviour compared to the number of public view points at each fossa's enclosure.

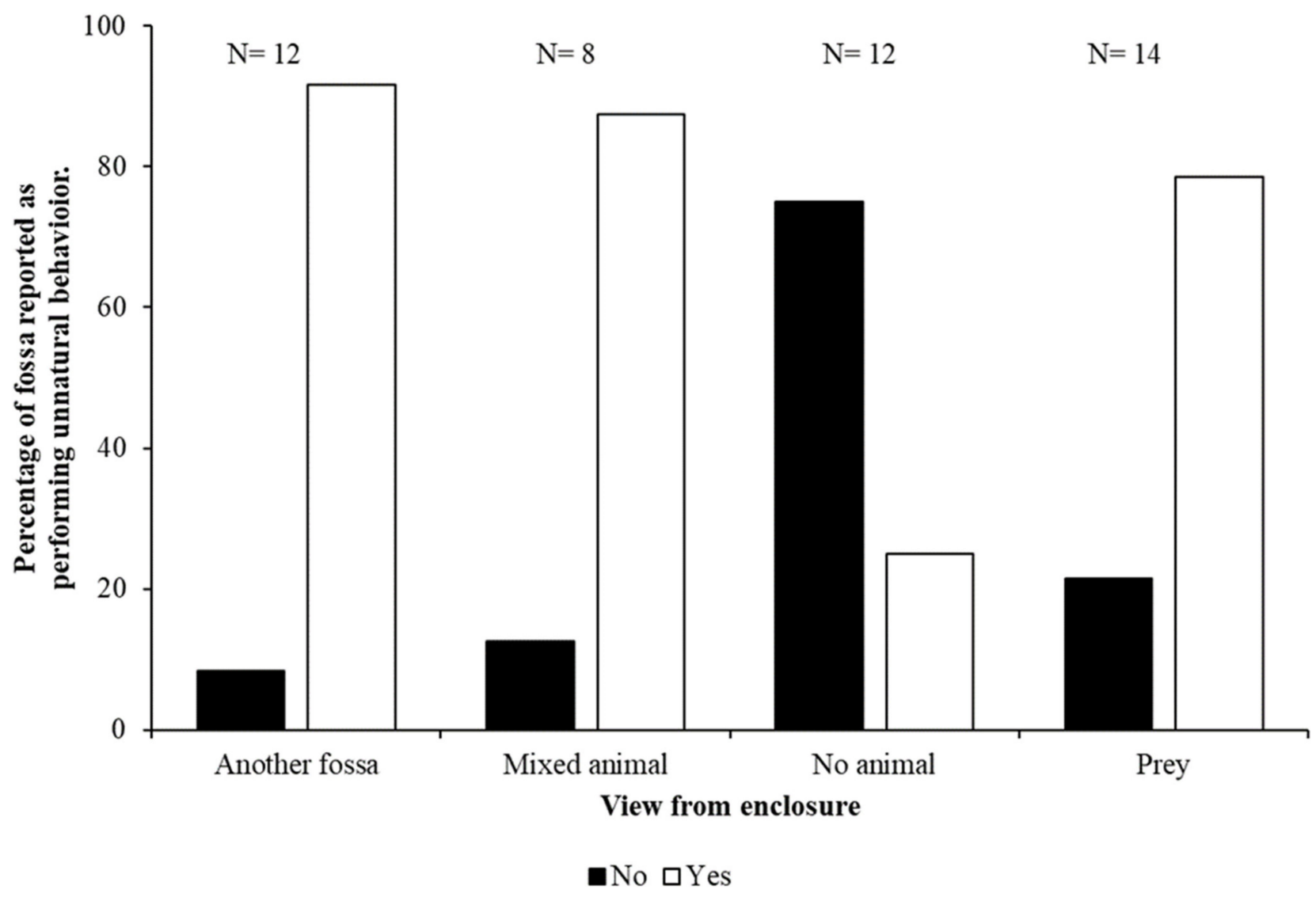

Figure 5. The view that each fossa had from its enclosure and the count of animals seen performing abnormal repetitive behaviour. 
All fossa were provided with enrichment and 27 fossa were trained by their facility. Forty-six (all) fossa were provided with nutritional (food or taste enrichment), 23 fossa experienced auditory enrichment, 41 had tactile enrichment, 30 had visual enrichment, 32 had cognitive enrichment, 18 experienced social enrichment and 44 animals were kept in exhibits where the physical features of the enclosure were enriching.

A more frequent schedule of enrichment was provided to fossa that performed unnatural behaviour (68\%) compared to animals that did not perform unnatural behaviour $(32 \%)$. More fossa were reported as performing unnatural behaviour in an enclosure with limited cover $(50 \%)$ whereas only six cases $(19 \%)$ were reported in enclosures that provided dense cover. The limited number of wild-caught animals in the sample population meant no meaningful analysis of reports of unnatural behaviour compared to the origin of the fossa (wild or zoo-born) could be undertaken. A higher percentage of adult $(89 \%)$ and old adult $(62 \%)$ fossa were reported as performing unnatural behaviour compared to young animals (43\%).

The lowest reports of unnatural behaviour were for animals with a variable time schedule for feeding throughout the day (13\% reported unnatural behaviour with a varied schedule compared to $34 \%$ with a once-a-day feed and $53 \%$ with a twice-day-feed). No cases of anticipatory behaviour were reported for animals with a variable feeding strategy. A twice-day-feed provided the highest reports of anticipatory behaviour (67\%) and pacing (56\%) for all fossa.

Details on heated nest boxes were provided for 38 animals. Only seven animals (six facilities) were provided with a heated nest box. Thirty-one animals had no heated nest box (18 facilities).

\subsection{Breeding}

Twenty-two animals in the sample were housed with the intention of breeding and 13 animals had actually bred. All except one of these animals were captive bred and all except two animals were classed as older adults (over 10 years old) with these two remaining individuals classed as adult. Results may therefore be confounded by the number of young, non-breeding animals in the survey population.

For the 36 fossa where all enclosure dimensions were provided, animals that had bred were provided with larger outdoor areas $\left(95.3 \pm 19 \mathrm{~m}^{2}\right)$ compared to $74.1 \pm 13.9 \mathrm{~m}^{2}$, and larger indoor areas too $\left(15.56 \pm 5.31 \mathrm{~m}^{2}\right.$ against $\left.13.1 \pm 2.17 \mathrm{~m}^{2}\right)$. Figure 6 illustrates enclosure dimensions for reproductively active/inactive animals.

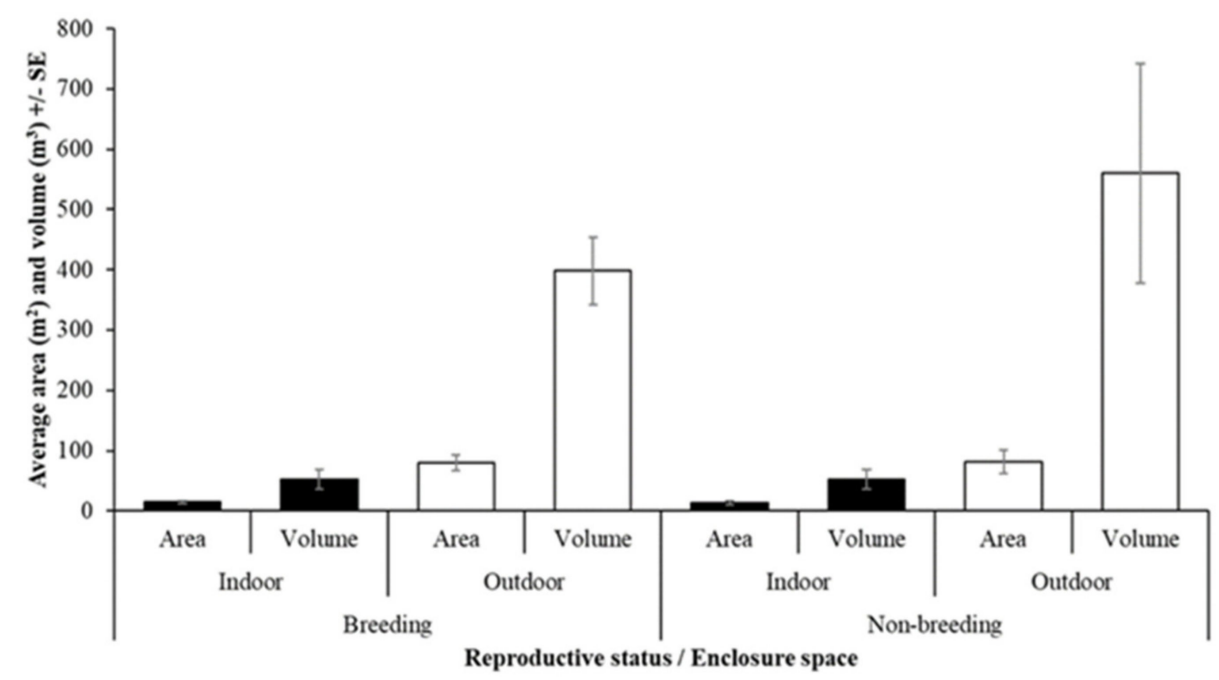

Figure 6. Comparison of mean indoor and outdoor area and volume for breeding and non-breeding fossa in this sample of zoos. 
There seems to be no clear relationship between reproductive activity and the number of nest boxes provided to captive fossa (Figure 7) except for where no nest box is available, no breeding occurs.

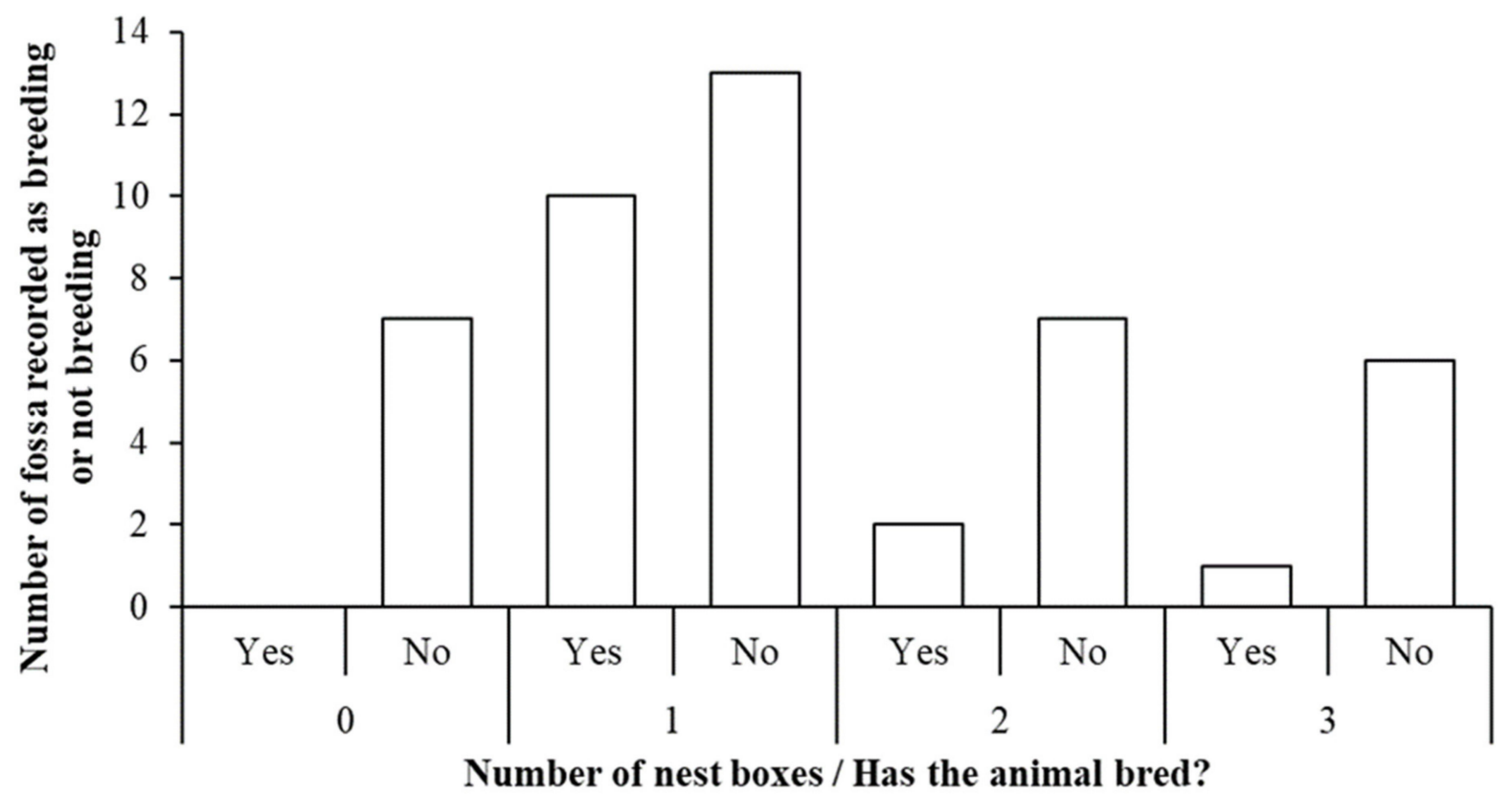

Figure 7. The relationship between the number of nest boxes provided and reports of breeding activity in this sample of captive fossa.

\section{Discussion}

These results represent a thorough analysis of fossa H\&H across North American, European and Asian facilities. Our study found that most fossa are ten years of age or older, housed singly, and the majority of fossa expressed unnatural behaviours, with pacing behaviour the most frequently observed. All fossa received enrichment, and most had public access restricted to one or two sides. The majority of these fossa had either another fossa or other animal in proximity to its enclosure and most fossa were locked in/out as part of their daily management. Forty-one percent of the fossa surveyed as breeding individuals bred at the zoo and four facilities with current non-breeding individuals, had previously bred at their zoo.

Housing area and volume varied greatly across facilities. Initially, the European standards recommended an outdoor exhibit space of at least $20 \mathrm{~m}^{2}$, with an exhibit height of at least $2.5 \mathrm{~m}$, and an indoor area of at least $10 \mathrm{~m}^{2}$ for a total of $30 \mathrm{~m}^{2}[39,41]$. However, as fossa are prone to developing abnormal repetitive behaviours (ARBs) when housed in small enclosures lacking complexity, it was determined that these dimensions were not adequate [39]. The AZA small carnivore TAG and European guidelines currently recommend a larger size of at least $50 \mathrm{~m}^{2}$ with a minimum vertical height of six meters for AZA and more than three meters for European standards [39,40]. Thirty-nine percent of collections that provided all enclosure measurements did not meet the prescribed exhibit size recommendations. Forty-four percent of fossa were housed in enclosures that met AZA criteria for exterior height, and 89\% met European guidelines. However, there was a marked decrease for indoor height, with only $6 \%$ of fossa having interior spaces with heights of six meters and $31 \%$ with heights over three meters.

Husbandry guidelines suggest that it is essential that sibling pairs (before reaching maturity) or females raising young are housed in spacious exhibits $[39,40]$. When housing two individuals together, the space recommendation increases to $89 \mathrm{~m}^{2}$ [39]. Of the eight animals housed in pairs, two were in an enclosure that did not meet the specified husbandry recommendations. In addition, in this study, females were provided with more space than 
males. Fossa have large home ranges and travel between 5 and $7 \mathrm{~km}$ per day [23,25]. Two radio collared male fossa tracked in western Madagascar had home-range sizes of 22.7 to $26.2 \mathrm{~km}^{2}$ with females ranging from 7.84 to $12.69 \mathrm{~km}^{2}$, indicating that males have 2-3 times the home range of females [26]. In several studies, species where males occupy larger home ranges and travel further than females in the wild paced more in managed care, e.g., okapi (Okapia johnstoni) [42], common wombats (Vombatus ursinus; [43] and Prezwalski horses (Equus ferus prezewalksii) [44]. Adding to the complexity of species management is that a zoo animal's response to confinement challenges may be multifactorial, and simply the provision of a larger space for a wide-ranging species may not mitigate abnormal behaviour. For example, Kroshko [7] found that the relationship between home range size and pacing is not always mediated by an animals daily traveling distance. Instead, some other aspect of being wide-ranging induces this behavioural response, e.g., a need for novelty. Novelty in this instance refers to wide-ranging mammalian carnivores only covering a portion of their overall range daily and naturally moving from place to place, (e.g., different denning areas) throughout the year [7]. Despite the homeostatic needs of wide-ranging species being met in managed care, facets of these lifestyles cannot be readily relinquished as they are driven by internally motivated behaviour (behavioural needs) that promote fitness in the wild [7]. In turn, pacing behaviour may manifest because of an inability to cope in their environment [45]. In our study, we also found that adult fossa (5-10 years of age) and older adults (10+) performed the most unnatural behaviour and were also housed in enclosures with interior and exterior space smaller than animals between 1-5 years of age. While recommendations suggest larger enclosure for sibling pairs and females raising young further research into the size, quality and shape of space, for fossa of all ages is suggested.

Unnatural behaviour increased in prevalence at enclosures with two or three public viewing points compared to those with 0 or 1 public viewing areas. Current husbandry recommendations suggest public access should be limited to one or two sides of their habitat to enable fossa to retreat from public disturbance $[39,40]$. The majority of facilities met these recommendations, with only $7 \%$ of fossa housed in an enclosure that featured three public viewing sides. The nature of a zoo's mission may be to immerse people with wildlife, which results in design protocols that preclude visual and auditory barriers between animals and visitors. However, visitor proximity to animals in a captive setting may be closer than what is comfortable to an animal [10]. Deleterious behavioural response to visitors has been documented in numerous species, particularly in nonhuman primates $[46,47]$ and felids [48,49]. Although some studies have found individual differences in animals [50] as well as positive or neutral responses to visitor presence [51,52]; most studies examining visitor effects found that zoo visitors cause stress to animals [53]. Despite most of the facilities meeting the prescribed husbandry recommendations for public access for fossa, the propensity of unnatural behaviour (particularly pacing) witnessed by survey respondents suggests that aspects of the current practices are insufficient. Visitor studies are deficient on the effect of visitors on fossa behaviour, and further research in this area would help determine appropriate public viewing points.

Although there are a few incidences of communal hunting [22] the fossa is generally a solitary species. While, male home-ranges may overlap, females have exclusive ranges and interaction with conspecifics is typically limited to brief periods during the breeding season [23]. The results indicate that fossa expressed more unnatural behaviours when in view of conspecifics and other species. Males exhibited these behaviours more frequently than females. Two collections noted that pacing was exacerbated when females were in estrus, or the fossa were housed in the proximity of the opposite sex. Year-round housing in proximity to conspecifics may create over-stimulation. For example, as the male attempts to reach a receptive female (or disperse from the female), he is repeatedly thwarted, from accessing or effectively moving out of olfactory, auditory or visual sight of the female; this may, in turn, result in frustration-induced abnormal repetitive behaviours [54]. The 'coping hypothesis' maintains that stereotypical behaviour may enable an animal to successfully cope with a stressful environment [55]. Pacing may be a coping function to alleviate inter- 
vals of arousal and may not always be correlated with systems associated with stress, such as higher glucocorticoid secretion [56]. However, evidence indicates that eliminating or reducing the need for stereotypic behaviour is linked to greater animal welfare [57] and, therefore, the chances of a more natural life in the zoo. Nonetheless, it is important to note that in some cases preventing stereotypes from occurring may increase arousal [58-60] or their eradication may not be possible due history (prior to zoo arrival) which may have triggered the need for behaviour [45]. Therefore, the overall management goal should be to mitigate for pacing behaviour before it is expressed. Facilities should ensure the recommended distance between individual pairs of $10 \mathrm{~m}$ [40] has been met or consider increasing distances. Additionally, facilities should ensure effective auditory and visual barriers are constructed between males and females outside of breeding season/introductions.

Sixty-five percent of the fossa in this study were either locked-in or locked-out for a portion of their day. A greater occurrence of unnatural behaviour were also reported for animals that were not provided with free access to interior and exterior aspects of their enclosure. Evidence is widely available on the subject and suggests that empowering captive animals with the freedom to choose benefits their wellbeing [61-64]. For example, Ross [65] noted that allowing polar bears (Ursus maritimus) to access an off-show den had a substantial positive effect on behaviours, reducing stereotypies, and increasing species-specific behaviour. Ensuring animals have unrestricted access to all aspects of their enclosure outside of feeding and cleaning should be a husbandry priority. If this is not plausible, providing fossa with additional opportunities to make choices and control their environment is essential.

In this study, feeding schedule influenced pacing and anticipation behaviour. Fossa fed twice per day were reported to express more anticipatory and pacing behaviour then those fed once or three times per day. Fossa that were fed on variable schedule (no set time throughout the day) had the lowest occurrence of unnatural behaviour and no anticipatory behaviour were reported. Anticipatory behaviour is expressed in the time between the signaling of an event and the occurrence of the event (e.g., food delivered, or allowed interior/exterior access). Anticipatory behaviour can be exacerbated due to highly predictable feeding times and routines [2]. Use of anticipatory behaviour as an indicator of an animal's emotional state has been postulated $[66,67]$ and, at present, only a limited number of small $\mathrm{N}$ studies have explored anticipatory behaviour as an indicator of zoo animal welfare [2,68]. Although, husbandry practices across zoos are carried out in relatively similar operating hours, variability within that time is achievable. Irrespective of whether anticipatory behaviour is considered as an indicator of an animal's desire for the next positive event, e.g., feeding or moving inside/outside or not, wild and free-living animals do not express these behaviours. When a free-living animal's homeotstatic imbalance triggers a strong drive for feeding, the animal has autonomy or agency and responds to the physiological mechanisms of hunger by hunting or consuming food. An animal lacking agency cannot express appetitive or consummatory behaviour as a response to hunger and in turn may respond with anticipatory behaviour or stereotypic behaviour [8,69]. Although, some studies have found evidence of dopamine release during the expression of anticipatory behaviour [67,70]. Elevated levels of dopamine are not always associated with the experience of pleasure [71] and that the interpretation of the role of mesolimbic dopamine may be 'wanting' [72], a state that is not necessarily positive [73]. Although, we may not be able to replicate the wild in our enclosure designs and the methods we use to drive 'naturalistic behaviour' are indeed, not necessarily components of an animal's natural environment (e.g., training, artificial enrichment devices, [74]), the expression of unnatural behaviours by their very nature are a limiting factor for the expression of species-specific behaviours. Thus, it is important to acknowledge such in moving forward with welfare assessment and ecologically informed husbandry.

A complex environment may reduce stress by increasing more scope for animals to express species-specific behaviours, thus decreasing unnatural behaviours [75] and potentially improving reproductive potential [76]. The AZA Guidelines (2011) specify the 
use of environmental enrichment with fossa including sensory (e.g., scent trails, herbs, nature sounds), food-based (e.g., scatter feeds, hiding food, horsetails), manipulative (e.g., cardboard boxes, boomer toys, antlers) and physical environment (e.g., furniture change, varied substrates). All collections in this study reported the use of food/taste-based enrichment, with most zoos also utilizing tactile/manipulation and olfactory/sensory enrichment practices. Fossa that expressed more unnatural behaviour received more opportunities for enrichment. EAZA and AZA guidelines recommend trees or artificial climbing structures with 'limbs' to provide usable vertical space for climbing and resting space for fossa $[39,40]$. However, twenty percent of surveyed zoos did not feature trees in the enclosure. Interestingly, $89 \%$ of those individuals housed in treeless exhibits expressed unnatural behaviour. More fossa were reported as performing unnatural behaviour in enclosures with limited cover compared to those reporting dense cover. Diminished environmental complexity is linked with increased predictability [69]. Research by Neave et al. [77] found that dairy calves $(\mathrm{N}=32)$ housed in unenriched (basic) pens performed more anticipatory behaviour for access to a reward pen (i.e., extra space) when compared to calves in enriched housing (enhanced environmental features), irrespective of whether the reward pen was unenriched or enriched. Unenriched calves also showed a decreased level of anticipatory behaviour when the reward quality was unexpectedly reduced whereas enriched calves increased anticipation with lowered reward quality. Therefore, calves in the unenriched environment were more sensitive to rewards and reward quality than calves that had enriched housing. Such research demonstrates the sensitivity of animals in impoverished environments to perform anticipatory activities and suggests that this may be a form of unnatural behaviour that is caused by the prevailing environmental conditions around the individual.

In the wild, fossa inhabit dense forests with large home ranges, travel several kilometers daily, have day/night activity patterns, and are adapted to hunt in the forest canopy and the ground. Without question, the fossa's behavioural ecology is complex. Characterisation of fossa anticipatory behaviour requires further study, but regardless of definition, expression of this behavioural type that restricts time on natural behaviours or important social interactions should be mitigated. Provision of increased frequency of species-specific individualized environmental enrichment is suggested for fossa, such as increasing cover, and adding natural trees for climbing to provide animals more opportunities to carry out highly motivated species-specific behaviours [78].

This study's limitations relate to the balance of scientific validity with the time constraints of those working in zoos to fill in a comprehensive H\&H survey. One approach to remedy this is that in future studies, would be to request photographs (with the survey) of enclosures including biologically relevant features/furnishings. Images could be collected as a tool to score specific aspects of enclosure design that may influence fossa behaviour (e.g., trees, climbing apparatus, vegetation (cover), nest boxes/retreat spaces). Thus, providing more objective measures of biologically relevant features. For example, level of cover could be scored against pre-defined photos of low, medium and high cover classifications rather than a classification centered on individual survey responder opinion. Finally, future research specifically focusing on the reproductive output of fossa would be beneficial, particularly with notable successes at individual facilities and where factors not addressed in the questionnaire may influence successful breeding.

\section{Conclusions}

This study has shown that there are numerous differences in the housing provided to, and the husbandry experienced by, captive fossa in facilities across three zoo regions. Fossa are likely to be perform unnatural behaviour in captivity, particularly pacing. It is clear from this survey that the fossa is a highly specialized animal with specific ecological and evolutionary features that need to be factored into its captive care. It is imperative that further research is conducted investigating the size, quality (environmental complexity 
linked to natural history) and the shape of fossa enclosure to pinpoint factors that may predict unnatural behaviour.

Supplementary Materials: The following are available online at https:/ / www.mdpi.com/article/10 .3390/jzbg2030028/s1, Survey S1: Fossa housing and husbandry questionnaire.

Author Contributions: Conceptualization, J.J.H. and L.O.; methodology, J.J.H. and L.O.; software, J.J.H. and P.E.R.; formal analysis, P.E.R.; investigation, J.J.H. and L.O.; resources, J.J.H. and P.E.R.; data curation, J.J.H.; writing-original draft preparation, J.J.H.; writing-review and editing, P.E.R.; visualization, J.J.H. and P.E.R.; project administration, J.J.H. All authors have read and agreed to the published version of the manuscript.

Funding: This research received no external funding.

Institutional Review Board Statement: The study was ethically reviewed, and all procedures were approved by the Tayto Park Ethics Committee on 20 February 2017 (ref 2017.2TPR).

Informed Consent Statement: Informed consent was obtained from all subjects involved in the study.

Data Availability Statement: The data that support the findings of this study are available from the corresponding author, J.J.H., upon reasonable request.

Acknowledgments: The authors wish to thank ABQ Bio Parc, Artis Amsterdam Royal Zoo, City of Belfast Zoo, Calviac, Chessington, Greenboro Sciene Centre, Happy Hollow Park and Zoo, Houston Zoo, Lakeland Wildlife Oasis, Lincoln Childrens Zoo, Little Rock Zoo, Marwell Zoo, Micke Grove Zoo, Newquay Zoo, Olmense Zoo, Omaha's Henry Doorly Zoo \& Aquarium, Parco Natura Viva, Parken Zoo, Pittsburg Zoo, Port Lympne, Racine Zoo, Tayto Park, The Living Desert, Ueno Zoological Gardens, Ventura Wildlife Zoological Garden, and the Zoological Society of East Anglia Africa Alive for participation in this study. Special thanks to Aisling Power at Tayto Park for trialing and commenting on early versions of the survey.

Conflicts of Interest: The authors declare no conflict of interest.

\section{References}

1. Hosey, G.; Melfi, V.; Pankhurst, S. Zoo Animals: Behaviour, Management, and Welfare; Oxford University Press: New York, NY, USA, 2013.

2. Ward, S.J.; Sherwen, S.; Clark, F.E. Advances in applied zoo animal welfare science. Appl. Anim. Behav. Sci. 2018, 21 (Suppl. 1), 23-33. [CrossRef] [PubMed]

3. Rose, P.E.; Brereton, J.E.; Rowden, L.J.; De Figueiredo, R.L.; Riley, L. What's new from the zoo? An analysis of ten years of zoo-themed research output. Palgrave Commun. 2019, 5, 1-10. [CrossRef]

4. Mellor, E.; Brilot, B.; Collins, S. Abnormal repetitive behaviours in captive birds: A Tinbergian review. Appl. Anim. Behav. Sci. 2018, 198, 109-120. [CrossRef]

5. Clubb, R.; Mason, G.J. Captivity effects on wide-ranging carnivores. Nature 2003, 425, 473-474. [CrossRef] [PubMed]

6. Clubb, R.; Mason, G.J. Natural behavioural biology as a risk factor in carnivore welfare: How analysing species differences could help zoos improve enclosures. Appl. Anim. Behav. Sci. 2007, 102, 303-328. [CrossRef]

7. Kroshko, J.; Clubb, R.; Harper, L.; Mellor, E.; Moehrenschlager, A.; Mason, G. Stereotypic route tracing in captive Carnivora is predicted by species-typical home range sizes and hunting styles. Anim. Behav. 2016, 117, 197-209. [CrossRef]

8. Carlstead, K. Determining the causes of stereotypic behaviors in zoo carnivores: Toward appropriate enrichment strategies. Second nature: Environmental enrichment for captive animals. In Second Nature: Environmental Enrichment for Captive Animals; Smithsonian Books: Washington, DC, USA, 1998; pp. 172-183.

9. Veasey, J. Concepts in the care and welfare of captive elephants. Int. Zoo Yearb. 2006, 40, 63-79. [CrossRef]

10. Morgan, K.N.; Tromborg, C.T. Sources of stress in captivity. Appl. Anim. Behav. Sci. 2007, 102, 262-302. [CrossRef]

11. Rose, P.E.; Roffe, S.M. A Case Study of Malayan Tapir (Tapirus indicus) Husbandry Practice Across 10 Zoological Collections. Zoo Biol. 2013, 32, 347-356. [CrossRef]

12. Rowden, L.J.; Rose, P.E. A global survey of banteng (Bos javanicus) housing and husbandry. Zoo Biol. 2016, 35, 546-555. [CrossRef]

13. Fuller, G.; Kuhar, C.W.; Dennis, P.M.; Lukas, K.E. A Survey of Husbandry Practices for Lorisid Primates in North American Zoos and Related Facilities. Zoo Biol. 2013, 32, 88-100. [CrossRef]

14. Wall, E.L.; Hartley, M. Assessing enclosure design and husbandry practices for successful keeping and breeding of the Burmese brow antlered deer (Eld's deer, Rucervus eldii thamin) in European zoos. Zoo Biol. 2017, 36, 201-212. [CrossRef]

15. Tennant, K.; Segura, V.; Morris, M.; Denninger Snyder, K.; Bocian, D.; Maloney, D.; Maple, T. Achieving optimal welfare for the Nile hippopotamus (Hippopotamus amphibius) in North American zoos and aquariums. Behav. Process. 2018, 156, 51-57. [CrossRef] 
16. Rose, P.; Rowden, L.J. for the Swamp, Catered for in Captivity? A Cross-Institutional Evaluation of Captive Husbandry for Two Species of Lechwe. Animals 2020, 10, 1874. [CrossRef]

17. Hawkins, F. Cryptoprocta ferox. The IUCN Red List of Threatened Species 2016: e.T5760A45197189. 2016. Available online: https:/ /dx.doi.org/10.2305/IUCN.UK.2016-1.RLTS.T5760A45197189.en (accessed on 19 July 2019).

18. Brooke, Z.M.; Bielby, J.; Nambiar, K.; Carbone, C. Correlates of Research Effort in Carnivores: Body Size, Range Size and Diet Matter. PLoS ONE 2014, 9, e93195. [CrossRef] [PubMed]

19. Gerber, B.D.; Karpanty, S.M.; Randrianantenaina, J. The impact of forest logging and fragmentation on carnivore species composition, density, and occupancy in Madagascar's rainforests. Oryx 2012, 46, 414-422. [CrossRef]

20. Hawkins, C.E.; Racey, P.A. Food habits of an endangered carnivore, Cryptoprocta ferox, in the dry deciduous forests of western Madagascar. J. Mammal. 2008, 89, 64-74. [CrossRef]

21. Hawkins, C.; Racey, P. Low population density of a tropical forest carnivore, Cryptoprocta ferox: Implications for protected area management. Oryx 2005, 39, 35-43. [CrossRef]

22. Lührs, M.-L.; Dammhahn, M. An unusual case of cooperative hunting in a solitary carnivore. J. Ethol. 2009, 28, 379-383. [CrossRef]

23. Hawkins, C. Cryptoprocta ferox. Fossa, Fosa. In The Natural History of Madagascar; Goodman, S., Benstead, J., Eds.; The University of Chicago Press: Chicago, IL, USA, 2003; pp. 1361-1363.

24. Lührs, M.-L.; Dammhahn, M.; Kappeler, P. Strength in numbers: Males in a carnivore grow bigger when they associate and hunt cooperatively. Behav. Ecol. 2012, 24, 21-28. [CrossRef]

25. Veron, G.; Dupré, D.; Lührs, M.-L.; Kappeler, P.M.; Dollar, L.; Pomerantz, J.; Goodman, S.M. Genetic polymorphism and structure of wild and zoo populations of the fosa (Eupleridae, Carnivora), the largest living carnivoran of Madagascar. Mamm. Biol. 2018, 92, 68-77. [CrossRef]

26. Hawkins, C. The Behaviour and Ecology of the Fossa, Cryptoprocta ferox (Carnivora: Viverridae) in a Dry Deciduous Forest in Western Madagascar; University of Aberdeen: Aberdeen, UK, 1998.

27. Hawkins, F.; Racey, P.A. A novel mating system in a solitary carnivore: The fossa. J. Zool. 2009, 277, 196-204. [CrossRef]

28. Hawkins, C.E.; Dallas, J.F.; Fowler, P.A.; Woodroffe, R.; Racey, P.A. Transient masculinization in the fossa, Cryptoprocta ferox (Carnivora, Viverridae). Biol. Reprod. 2002, 66, 610-615. [CrossRef] [PubMed]

29. Hornsey, T. Breeding the fossa at Suffolk Wildlife Park. Int. Zoo Yearb. 1999, 46, 407-417.

30. Albignac, R. Breeding the fossa at Montpellier Zoo. Int. Zoo Yearb. 1975, 15, 147-150. [CrossRef]

31. Krebs, M.; Bryan, C. Population Analysis and Breeding and Transfer Plan Fossa (Cryptoprocta ferox) AZA Species Survival Plan Yellow Program; Omaha Zoo: Omaha, NE, USA, 2012; p. 20.

32. Species360 Zoological Information Management System (ZIMS). 2018. Available online: https://zims.species360.org/Login. aspx?ReturnUrl=\%2f (accessed on 2 March 2017).

33. Reiter, J.; Winkler, A. EEP Studbook for the Fossa (Cryptoprocta ferox) Edition 2012; European Association of Zoos and Aquaria: Amsterdam, The Netherlands, 2012.

34. Pfleiderer, J. Fossa (Cryptoporcta ferox); EEP Annual Report 2017; EAZA: Amsterdam, The Netherlands, 2017.

35. Krebs, M. Email correspondence. 23 April 2019.

36. Farris, Z.J.; Gerber, B.D.; Karpanty, S.; Murphy, A.; Andrianjakarivelo, V.; Ratelolahy, F.; Kelly, M.J. When carnivores roam: Temporal patterns and overlap among M adagascar's native and exotic carnivores. J. Zool. 2015, 296, 45-57. [CrossRef]

37. McGowan, P.J.; Traylor-Holzer, K.; Leus, K. IUCN guidelines for determining when and how ex situ management should be used in species conservation. Conserv. Lett. 2017, 10, 361-366. [CrossRef]

38. Kitchener, A.C. Small carnivorans, museums and zoos. Int. Zoo Yearb. 2020. [CrossRef]

39. AZA Small Carnivore TAG. Mongoose, Meerkat, E Fossa (Herpestidae/Eupleridae) Care Manual; Association of Zoos and Aquariums: Silver Spring, MD, USA, 2011; p. 103.

40. Reiter, J.; Winkler, A. Husbandry Guidelines for the Fossa (Cryptoprocta ferox); European Association of Zoos and Aquaria: Amsterdam, The Netherlands, 2013.

41. Winkler, A. Husbandry Guidelines for the Fossa (Cryptoprocta ferox); Prepared for EAZA SCTAG Husbandry Guidelines; Duisberg Zoo: Duisburg, Germany, 2002.

42. Bennett, C.; Torgerson-White, L.; Fripp, D.; Watters, J.; Petric, A. A multi-institutional assessment of factors influencing locomotion and pacing in captive okapis (Okapia johnstoni). Appl. Anim. Welf. Sci. 2015, 18 (Supp. 1), S43-S61. [CrossRef]

43. Hogan, L.A.; Tribe, A. Prevalence and cause of stereotypic behaviour in common wombats (Vombatus ursinus) residing in Australian zoos. Appl. Anim. Behav. Sci. 2007, 105, 180-191. [CrossRef]

44. Boyd, L.E. Time budgets of adult Przewalski horses: Effects of sex, reproductive status and enclosure. Appl. Anim. Behav. Sci. 1998, 21, 19-39. [CrossRef]

45. Rose, P.E.; Nash, S.M.; Riley, L.M. To pace or not to pace? A review of what abnormal repetitive behaviour tells us about zoo animal management. J. Vet. Sci. 2017, 20, 11-21.

46. Hosey, G.R. How does the zoo environment affect the behaviour of captive primates? Appl. Anim. Behav. Sci. 2005, 90, 107-109. [CrossRef]

47. Quadros, S.; Goulart, V.D.; Passos, L.; Vecci, M.A.; Young, R.J. Zoo visitor effect on mammal behaviour: Does noise matter? Appl. Anim. Behav. Sci. 2014, 156, 78-84. [CrossRef] 
48. Sellinger, R.L.; Ha, J.C. The effects of visitor density and intensity on the behaviour of two captive jaguars (Panthera onca). J. Appl. Anim. Welf. Sci. 2015, 8, 233-244. [CrossRef]

49. Suárez, P.; Recuerda, P.; Arias-de-Reyna, L. Behaviour and welfare: The visitor effect in captive felids. Anim. Welf. 2017, 26, 25-34. [CrossRef]

50. Boyle, S.A.; Berry, N.; Cayton, J.; Ferguson, S.; Gilgan, A.; Khan, A.; Lam, H.; Leavelle, S.; Mulder, I.; Myers, R.; et al. Widespread Behavioural Responses by Mammals and Fish to Zoo Visitors Highlight Differences between Individual Animals. Animals 2020, 10, 2108. [CrossRef]

51. Nimon, A.J.; Dalziel, F.R. Cross-species interaction and communication: A study method applied to captive siamang (Hylobates syndactylus) and long-billed corella (Cacatua teuirostris) contacts with humans. Appl. Anim. Behav. Sci. 1992, 22, $261-272$. [CrossRef]

52. Margulis, S.W.; Hoyos, C.; Anderson, M. Effect of felid activity on zoo visitor interest. Zoo Biol. 2003, 22, 587-599. [CrossRef]

53. Fernandez, E.J.; Tamborski, M.A.; Pickens, S.R.; Timberlake, W. Animal-visitor interactions in the modern zoo: Conflicts and interventions. Appl. Anim. Behav. Sci. 2009, 120, 1-8. [CrossRef]

54. Mason, G.; Clubb, R.; Latham, N.; Vickery, S. Why and how should we use environmental enrichment to tackle stereotypic behaviour? Appl. Anim. Behav. Sci. 2007, 102, 163-188. [CrossRef]

55. Cooper, J.J.; Nicol, C.J. The 'coping' hypothesis of stereotypic behaviour: A reply to Rushen. Anim. Behav. 1993, 45, 616-618. [CrossRef]

56. Wechsler, B. Coping and coping strategies: A behavioural view. Appl. Anim. Behav. Sci. 1995, 43, 123-134. [CrossRef]

57. Maple, T.L.; Perdue, B.M. Zoo Animal Welfare; Springer: Berlin/Heidelberg, Germany, 2013.

58. Kennes, D.; de Rycke, P.H. Influence of performance of stereotypies on plasma corticosterone and leucocyte levels in the bank vole (Clethrionomys glareolus). In Proceedings of the International Congress on Applied Ethology in Farm Animals; Unshelem, G., van Patten, K., Zeeb, K., Eds.; Kuratorium für Technik und Bauwesen in der Landwirtschaft: Darmstadt, Germany, 1988; pp. 238-240.

59. McGreevy, P.D.; Nicol, C.J. The effect of short-term prevention on the subsequent rate of crib-bitting in Thoroughhred horses. Equine Vet. J. 1998, 27, 30-34.

60. McBride, S.D.; Cuddeford, D. The putative welfare-reducing effects of preventing equine stereotypic behaviour. Anim. Welf. 2001, 10, 173-189.

61. Markowitz, H.; Aday, C. Power for captive animals. In Second Nature: Environmental Enrichment for Captive Animals; Shepherdson, D., Forthman, D.L., Eds.; Smithsonian Institution Press: Washington, DC, USA, 1998; p. 47.

62. Owen, M.A.; Swaisgood, R.R.; Czekala, N.M.; Lindburg, D.G. Enclosure choice and well-being in giant pandas: Is it all about control? Zoo Biol. 2005, 24, 475-481. [CrossRef]

63. McPhee, M.E.; Carlstead, K. The Importance of Maintaining Natural Behaviours in Captive Mammals. In Wild Mammals in Captivity: Principles and Techniques for Zoo Management; University of Chicago Press: Chicago, IL, USA, 2010; pp. 303-313.

64. Kurtycz, L.M.; Wagner, K.E.; Ross, S.R. The choice to access outdoor areas affects the behaviour of great apes. J. Appl. Anim. Welf. Sci. 2014, 17, 185-197. [CrossRef]

65. Ross, S.R. Issues of choice and control in the behaviour of a pair of captive polar bears (Ursus maritimus). Behav. Process. 2006, 73, 117-120. [CrossRef] [PubMed]

66. Watters, J.V. Searching for behavioral indicators of welfare in zoos: Uncovering anticipatory behavior. Zoo Biol. 2014, 33, 251-256. [CrossRef] [PubMed]

67. Spruijt, B.M.; Van den Bos, R.; Pijlman, F.T.A. A concept of welfare based on reward evaluating mechanisms in the brain: Anticipatory behaviour as an indicator for the state of reward systems. Appl Anim Behav Sci. 2001, 72, 145-171. [CrossRef]

68. Jensen, A.L.; Delfour, F.; Carter, T. Anticipatory behavior in captive bottlenose dolphins (Tursiops truncatus): A preliminary study. Zoo Biol. 2013, 32, 436-444. [CrossRef]

69. Bassett, L.; Buchanan-Smith, H.M. Effects of predictability on the welfare of captive animals. Appl. Anim. Behav. Sci. 2007, 102, 223-245. [CrossRef]

70. Berridge, K.C. Food reward: Brain substrates of wanting and liking. Neurosci. Biobehav. Rev. 1996, 20, 1-25. [CrossRef]

71. Wise, R.A. Dopamine and reward: The anhedonia hypothesis 30 years on. Neurotox. Res. 2008, 14, 169-183. [CrossRef]

72. Berridge, K.C. The debate over dopamine's role in reward: The case for incentive salience. Psychopharmacology 2007, 191, 391-431. [CrossRef]

73. Anderson, C.; von Keyserlingk, M.A.G.; Lidfors, L.M.; Weary, D.M. Anticipatory behaviour in animals: A critical review. Anim. Welf. 2020, 29, 231-238. [CrossRef]

74. Watters, J.V.; Krebs, B.L.; Eschmann, C.L. Assessing Animal Welfare with Behavior: Onward with Caution. J. Zool. Bot. Gard. 2021, 2, 75-87. [CrossRef]

75. Swaisgood, R.R.; Shepherdson, D.J. Scientific approaches to enrichment and stereotypies in zoo animals: What's been done and where should we go next? Zoo Biol. 2005, 24, 499-518. [CrossRef]

76. Carlstead, K.; Shepherdson, D. Alleviating stress in zoo animals with environmental enrichment. In The Biology of Animal Stress: Basic Principles and Implications for Animal Welfare; University of California: Davis, CA, USA, 2000; pp. 337-354. 
77. Neave, H.W.; Webster, J.R.; Zobel, G. Anticipatory behaviour as an indicator of the welfare of dairy calves in different housing environments. PLoS ONE 2021, 16, e0245742. [CrossRef] [PubMed]

78. Mendl, M.; Burman, O.H.P.; Paul, E.S. An integrative and functional framework for the study of animal emotion and mood. Proc. R. Soc. B 2010, 277, 2895-2904. [CrossRef] [PubMed] 